IRRITABLE BOWEL SYNDROME

\title{
Symptom patterns in functional dyspepsia and irritable bowel syndrome: relationship to disturbances in gastric emptying and response to a nutrient challenge in consulters and non-consulters
}

\author{
S Haag, N J Talley, G Holtmann
}

Gut 2004;53:1445-1451. doi: 10.1136/gut.2003.030049

See end of article for authors' affiliations

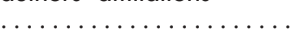

Correspondence to: Dr G Holtmann,

Department of

Gastroenterology,

Hepatology, and 'General

Internal Medicine, Royal

Adelaide Hospital,

University of Adelaide,

North Terrace, Adelaide,

South Australia 5000,

Australia; gerald.

holtmann@web.de

Accepted for publication

4 February 2004
Background: Our aim was to assess the relationship between gastric motor and sensory function and symptom patterns in community subjects and patients with functional dyspepsia (FD) or irritable bowel syndrome (IBS).

Methods: We recruited 291 asymptomatic blood donors, 151 symptomatic blood donors (recurrent abdominal pain or discomfort), and 40 patients with FD or IBS. Abdominal symptoms were assessed using the bowel disease questionnaire (BDQ) and, in addition, the most bothersome symptom complex identified (dysmotility-type, ulcer-type dyspepsia, or IBS). Gastric emptying time (GET $\left(t_{1 / 2}, \mathrm{~min}\right)$ ) was measured by ${ }^{13} \mathrm{C}$-octanoic breath test and a nutrient challenge performed. Twenty randomly selected asymptomatic blood donors, 48 symptomatic blood donors (30 FD, 18 IBS), and 40 patients (23 FD, 17 IBS) had additional function testing.

Results: GET $\left(t_{1 / 2}\right)$ was significantly $(p<0.05)$ longer in blood donors with FD symptoms $(99(6) \mathrm{min})$ and FD patients (110 (12) $\mathrm{min}$ ) compared with asymptomatic controls (76.7 (7) $\mathrm{min})$, but was not significant in IBS blood donors or patients. Overall, 25 of 48 blood donors with symptoms and 18 of 40 patients had slow gastric emptying. GET was most delayed in subjects with predominantly dysmotility-type symptoms (167 (36) min $v$ controls; $p<0.01$ ). Symptom intensities after a nutrient challenge were significantly higher in FD patients and symptomatic blood donors compared with asymptomatic controls; 14 of 48 blood donors with symptoms and 16 of 40 patients had a symptom response to the nutrient challenge exceeding the response (mean (2SD)) of healthy asymptomatic controls.

Conclusion: Gastric emptying and the global symptom response to a standardised nutrient challenge are abnormal in population based (non-health care seeking) subjects with dyspepsia.
$\mathrm{F}$ unctional gastrointestinal disorders (FGID) are clinical syndromes defined by chronic or recurrent abdominal symptoms without identifiable cause using conventional diagnostic measures. ${ }^{1}$ Functional abdominal symptoms are highly prevalent in the general population; many do not seek health care but the intensity of symptoms may be one factor promoting the seeking of medical assistance. ${ }^{2}$ In functional dyspepsia (FD) and irritable bowel syndrome (IBS), symptoms are frequently related to meals and can include abdominal pain, bloating, early satiety, fullness, belching, and nausea. ${ }^{1}$ The aetiology of FD is unknown but various pathophysiological mechanisms may account for them. Impaired meal induced relaxation of the proximal stomach, ${ }^{3}{ }^{4}$ visceral hypersensitivity to distension, ${ }^{356}$ gastric motor abnormalities, ${ }^{7}$ as well as disturbed central nervous function $^{89}$ have all been implicated as important pathophysiological mechanisms causing dyspeptic symptoms, but overlap is frequent.

It has been demonstrated that approximately $40 \%$ of patients with FD have impaired gastric emptying, and this has been linked to fullness. ${ }^{10}$ Boeckxstaens and colleagues ${ }^{11} 12$ reported impaired ability to drink a normal nutrient meal volume but did not find a correlation between drinking capacity and specific dyspeptic symptoms. On the other hand, Tack et al recently reported a correlation between impairment of meal induced proximal stomach relaxation and a drink test in FD. ${ }^{13}$ However, it is not known if these pathophysiological abnormalities are associated with symptom clusters, as defined by the Rome I criteria. In addition, previous studies may have been biased because they focused on patients referred to tertiary referral centres, presumably for refractory symptoms. Data on the relationship between disturbed gastrointestinal motor and sensory abnormalities in patients not referred to tertiary centres are lacking and similarly, no population based data are available.

Our aims in the present study were: (a) to determine the relationship between gastric motor abnormalities and an abnormal nutrient drink test in a population based sample of subjects with and without symptoms, and in patients evaluated in a tertiary care centre; and (b) to assess whether specific functional gastrointestinal disturbances are related to the most bothersome symptoms in the population. We hypothesised that (1) gastric emptying would be delayed in patients and this would be more likely in subjects with predominantly dysmotility-type symptoms and (2) the global symptom response to a standardised nutrient challenge would be increased in subjects with dyspeptic symptoms and in symptomatic patients with FD.

Abbreviations: $B D Q$, bowel disease questionnaire; $F D$, functional dyspepsia; FGID, functional gastrointestinal disorder; GET, gastric emptying time; IBS, irritable bowel syndrome; GORD, gastrooesophageal reflux disease 


\section{MATERIAL AND METHODS \\ Subjects}

The study protocol was approved by the Institutional Review Board of the University of Essen. During an eight week period, 442 consecutive blood donors were recruited for the study. After giving informed consent, all volunteers underwent a physical examination and laboratory screening (sedimentation rate, red and white blood cell count, transaminases, gamma glutamyltransferase, hepatitis B and $\mathrm{C}$ antibodies, as well as HIV antibodies). In addition, $10 \mathrm{ml}$ of blood were taken for determination of Helicobacter pylori antibodies (ELISA, Freiburg, Germany). Preparation of the antigen was performed according to the method previously described by Blaser and Duncan. ${ }^{14}$ The cut off value was set at $10 \mathrm{IU} / \mathrm{ml}$.

Subjects receiving any medication over an eight week period prior to blood donation (that is, antibiotics, antacids, prokinetics, proton pump inhibitors, $\mathrm{H}_{2}$ receptor antagonists, or non-steroidal anti-inflammatory drugs), those with a history of abdominal or gynaecological surgery, gastrointestinal cancer, peptic ulcer disease, and isolated or predominantly symptoms of gastro-oesophageal reflux disease (GORD) were identified by interview prior to blood donation and excluded from the study $(\mathrm{n}=8)$. A randomised screening for drugs and narcotics was performed; 10 subjects refused to participate in the study. Therefore, out of a population of 460 consecutive healthy blood donors, 442 (96.1\%; 241 female) participated in the trial. A flow chart of patient selection and study days is shown in fig 1 .

Forty consecutive patients (27 female, aged 27-40 years) with either FD or IBS referred to our institution for evaluation and treatment served as positive controls. Standardised workup included upper gastrointestinal endoscopy, abdominal sonography, and laboratory testing. Colonoscopy was also performed in all subjects aged $>45$ years and those with concomitant IBS symptoms.

\section{Assessment of abdominal symptoms}

To assess abdominal symptoms and intensity, all study participants were given a German version of the bowel disease questionnaire $\left(\mathrm{BDQ}^{15}\right)$, as described previously. ${ }^{16}$ This was completed prior to participation in the study. Study subjects were requested to grade the intensity of their symptoms (if any) on a scale ranging from 1 (mild) to 4 (extreme). All subjects were categorised according to the Rome II criteria by the same physician ( $\mathrm{SH}$ ) based on symptoms that were identified by the patient as the most bothersome $^{17}$ (that is, IBS; or ulcer-type, dysmotility-type, or non-specific FD). During the nutrient drink test on study day 2, symptoms (pain, fullness, nausea) were analysed by a symptom score on a visual analogue scale (range 0-100 mm).

\section{Study protocol}

Function testing was performed on two separate days at least seven days apart. Tests were performed in random sequence. On one study day, gastric emptying time (GET) was quantified with an ${ }^{13} \mathrm{C}$-octanoic acid breath test according to the method of Ghoos and colleagues. ${ }^{18}$ All tests were performed after an overnight fast. The test meal consisted of a scrambled egg with yolk doped with $100 \mathrm{mg}{ }^{13} \mathrm{C}$-octanoic acid. The egg was ingested with two slices of white bread and $10 \mathrm{~g}$ of margarine (total caloric load $300 \mathrm{kcal}$ ), and immediately followed by $150 \mathrm{ml}$ of water. After two hours, subjects were given another $150 \mathrm{ml}$ of water. Before the test, a breath sample was taken for baseline measurements. In the following four hours, breath samples were taken every 10 minutes during the first two hours and every 15 minutes for the last two hours of the test. Delayed gastric emptying was defined as a $t^{1} / 2$ greater than the $95 \%$ confidence interval (CI) in healthy volunteers. ${ }^{18}$

On another day, a standardised $600 \mathrm{ml}$ nutrient challenge (Fresubin; Fresenius, Germany; caloric density $1.5 \mathrm{kcal} / \mathrm{ml}$ : $3.8 \mathrm{~g}$ protein, $13.8 \mathrm{~g}$ carbohydrate, $3.4 \mathrm{~g}$ fat $/ 100 \mathrm{ml}$ ) was performed and symptoms (nausea, fullness, pain) assessed using a visual analogue scale (range $0-100 \mathrm{~mm}$ ) with $" 0 "=$ no symptoms or discomfort and " $100 "=$ very severe pain or discomfort. All subjects were asked to drink $200 \mathrm{ml}$ of the liquid meal every five minutes and reported their symptoms after a total of $600 \mathrm{ml}$ (or the maximum ingested volume if subjects did not tolerate $600 \mathrm{ml}$ ). We have shown previously that symptom response at a cumulated volume of $600 \mathrm{ml}$ is significantly correlated with the gastric volume threshold for discomfort measured with a barostat device. ${ }^{19}$

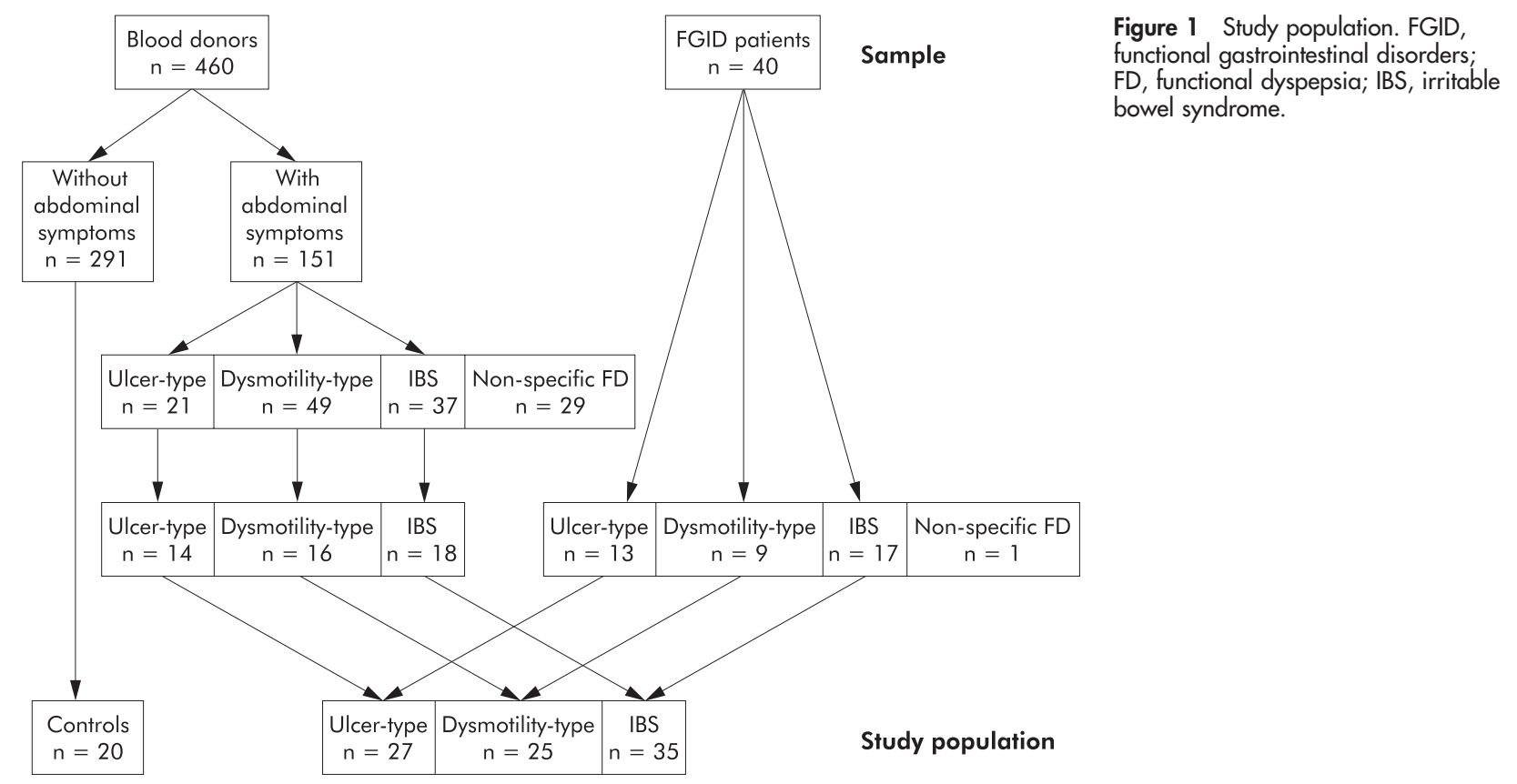

Figure 1 Study population. FGID, functional gastrointestinal disorders; FD, functional dyspepsia; IBS, irritable bowel syndrome. 
Table 1 Frequency of abdominal symptoms, sex, and age distribution in healthy blood donors and positive controls (patients)

\begin{tabular}{|c|c|c|c|c|c|c|c|}
\hline \multirow{3}{*}{$\begin{array}{l}\text { Predominant } \\
\text { symptom }\end{array}$} & \multicolumn{3}{|l|}{ Blood donors } & \multicolumn{4}{|l|}{ Study population } \\
\hline & \multirow{2}{*}{$\begin{array}{l}\text { Asymptomatic }(n=291) \\
\text { Females/males }\end{array}$} & \multicolumn{2}{|c|}{ Symptomatic $(n=136)$} & \multicolumn{2}{|c|}{ Blood donors $(n=48)$} & \multicolumn{2}{|l|}{ Patients $(n=40)$} \\
\hline & & Females & Males & Females & Males & Females & Males \\
\hline Dysmotility-type & - & $22(34.4(12.6))$ & $27(33(13.1))$ & $9(32.7(12.4))$ & $7(29.4(7.5))$ & $6(43.4(12.5))$ & $3(41.8(16.9))$ \\
\hline Ulcer-type & - & $11(29.3(10.3))$ & $10(41.6(7.8))$ & $9(28.6(8.9))$ & $5(43.2(10.6))$ & $9(44.9(15.8))$ & $4(48.0(2.9))$ \\
\hline Non-specific & - & $9(50.5(10.6))$ & $20(39.9(10.7))$ & 0 & 0 & 0 & $1(42)$ \\
\hline & - & $25(29.7(9.5))$ & $12(34.1(11.2))$ & $13(30.7(10.6))$ & $5(41.0(14.8))$ & $12(45.0(11.7))$ & $5(50.4(13.8))$ \\
\hline Total (n) & $\begin{array}{l}164 / 127(35.6(12.7)) / \\
(39.4(11.1))\end{array}$ & $67(33.1(11.6))$ & $69(37.3(11.5))$ & $31(30.7(10.5))$ & $17(35.4(12.4))$ & $27(44.9(12.7))$ & $13(47.0(12.3))$ \\
\hline
\end{tabular}

Values are number and (mean (2SD) age (years)).

IBS, irritable bowel syndrome.

\section{Statistical analyses}

Primary outcome variables were gastric emptying $\left(t^{1} 1 / 2, \min \right)$ and symptom response to the nutrient challenge $(600 \mathrm{ml})$.

Means (SD) for symptom intensity were calculated and groups compared. Analyses of variance were used for differences between blood donors with versus without symptoms and subgroups and patients from the outpatient clinic with regard to their symptoms. Log transformation was conducted prior to analysis if indicated. Alpha adjustment for the primary two target variables was applied. Analyses were conducted in a hierarchical manner (that is, differences in the primary outcome were initially tested in symptomatic versus asymptomatic subjects). Further comparisons were done only if the initial comparisons yielded significant differences.

All $\mathrm{p}$ values calculated were two tailed; an $\alpha<0.05$ was considered significant for primary parameters. All further (exploratory) analyses were considered significant at an $\alpha$ level of 5\%. Statistical analyses were performed using the Statistical Analysis System (SAS, release 6.12; SAS Institute Inc., Cary, North Carolina, USA ${ }^{20}$ ).

A sample size of at least 20 healthy subjects and at least 40 subjects with symptoms were needed to yield differences of more than $20 \%$ for the primary outcome variables with an $\alpha$ level of 0.025 and a $\beta$ level of 0.80 .

\section{RESULTS}

Overall, data from 442 blood donors (241 females, 201 males; aged 18-68 years) and 40 consecutive patients ( 27 females, 13 males; aged 23-70 years) with chronic abdominal symptoms but no anatomical or biochemical abnormalities to explain their symptoms (positive controls) were available. Due to an incomplete questionnaire with more than $25 \%$

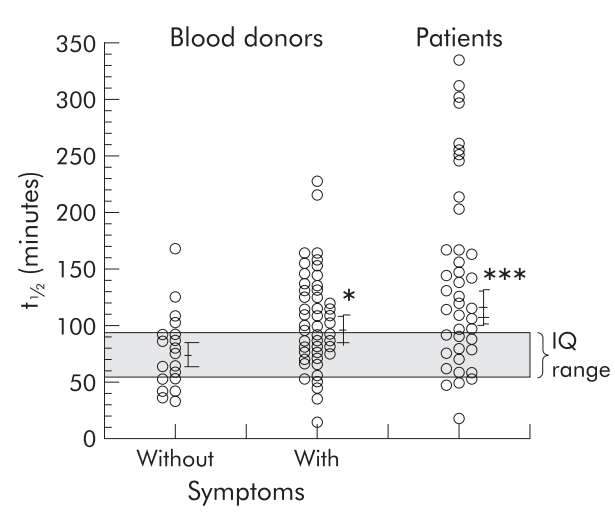

Figure 2 Gastric emptying time ( $t_{1 / 2}$ in minutes) of healthy blood donors with versus those without gastrointestinal symptoms, and of patients ( ${ }^{*} p<0.025,{ }^{* * *} p<0.001 v$ asymptomatic controls). Interquartile (IQ) range is given for healthy controls. missing data, one female blood donor could not be analysed and another 15 (10 female) blood donors with symptoms could not be classified for the same reason. Thus 136 subjects with recurrent abdominal symptoms were available for further evaluation.

\section{Gastrointestinal symptoms}

A total of 151 healthy blood donors $(34.2 \%$ (95\% CI $29.7-$ 38.6)) reported abdominal pain or discomfort on more than six occasions during the previous 12 months. Thirty seven blood donors (24.5\% (95\% CI 17.6-31.4)) identified IBS symptoms as the most bothersome symptom complex while the remainder reported predominantly symptoms consistent with FD ( $\mathrm{n}=21$ ulcer-type $13.9 \%$ (95\% CI 8.4-19.4); $\mathrm{n}=49$ dysmotility-type $32.5 \%$ (95\% CI 25.0-39.9); $\mathrm{n}=29$ nonspecific dyspepsia 19.2\% (95\% CI 12.9-25.5)). Fifteen blood donors (9.9\% (95\% CI 5.7-15.9)) reported recurrent abdominal symptoms but were not analysed further due to lack of additional information. Twenty five of 37 blood donors (67.6\% (95\% CI 50.2-82.0)) with IBS symptoms were female. In contrast, FD symptoms were predominantly reported by males (57.6\% (95\% CI 47.2-67.4)).

Twenty subjects (12 female) without any abdominal symptoms and 50 subjects with relapsing upper abdominal symptoms consistent with FD or IBS were randomly recruited from the blood donor population. Two refused to participate, leaving 68 subjects (43 women, 25 men; age range 1968 years). In addition, we studied 40 consecutive patients with chronic abdominal symptoms lasting for more than five years, consistent with FD or IBS, as a control group (27 women, 13 men; aged 23-70 years). The distribution of FD and IBS, based on the predominant symptom complex, as well as sex and age distribution are presented in table 1.

\section{Gastric emptying time}

Comparison of healthy controls with patients/blood donors with symptoms

Overall, gastric emptying was significantly longer in blood donors with abdominal symptoms compared with asymptomatic controls (99 (6) $v 76$ (7) minutes; $\mathbf{p}<0.01$ ). Similarly, GET was significantly delayed in patients compared with controls (110 (12) v 76 (7) minutes; $\mathrm{p}<0.01$ ) (table 2, fig 2). Nine of the investigated patients and two of the blood donors with symptoms had a GET exceeding 200 minutes, identifying a subgroup of FD patients with severely delayed GET. Overall, 25 of 48 blood donors with symptoms (52\%) and 18 of 40 patients with FD or IBS (45\%) had a gastric emptying rate that was not within the normal range (mean (2SD)) of healthy asymptomatic controls (tables 2, 3). Furthermore, comparing gastric emptying in subjects with FD (patients and blood donors) with healthy controls yielded a significantly delayed gastric emptying time (109 (15) v 76 (7) minutes; $\mathrm{p}<0.01)$. Similarly, GET was delayed in subjects with IBS 
Table 2 Gastric emptying time (GET, $\mathrm{t}_{1 / 2}$ (minutes)) of patients versus blood donors

\begin{tabular}{llcc}
\hline Predominant symptom & $\begin{array}{l}\text { Asymptomatic controls } \\
(\mathbf{n = 2 0 )}\end{array}$ & $\begin{array}{l}\text { Blood donors with symptoms } \\
(\mathbf{n = 4 8 )}\end{array}$ & Patients $(\mathbf{n = 4 0 )}$ \\
\hline GET & $76(7)$ & $99(6)^{*}$ & $110(12)^{*}$ \\
Dysmotility-type & - & $102(10)^{*}(n=16)$ & $167(36)^{* * *}(n=9)$ \\
Ulcer-type & - & $111(13)^{*}(n=14)$ & $76(10)(n=13)$ \\
IBS & - & $89(10)(n=18)$ & $106(18)^{*}(n=17)$ \\
\hline${ }^{*} p<0.025,{ }^{* * *} p<0.001$ versus asymptomatic controls. & \\
IBS, irritable bowel syndrome.
\end{tabular}

(patients and blood donors) compared with healthy controls (97 (14) $v 76$ (7) minutes; $\mathrm{p}<0.01$ ).

\section{Symptom type}

Mean GET was significantly delayed in blood donors with dysmotility-type and ulcer-type dyspepsia, but not in IBS, compared with asymptomatic controls. Similarly, patients with dysmotility-type dyspepsia and IBS had delayed GET but there was no significant abnormality in patients with ulcer-type dyspepsia (table 2). Overall, 11 of 22 patients with dysmotility-type or ulcer-type symptoms (50\%), and seven of 17 patients with IBS symptoms (41\%) had gastric emptying above the normal range of healthy asymptomatic controls (table 3).

\section{Nutrient challenge}

With the exception of two patients with dysmotility-type symptoms, all study subjects ingested $600 \mathrm{ml}$. These two patients ingested 520 and $500 \mathrm{ml}$, respectively, and symptom responses were otherwise recorded according to the protocol.

\section{Comparison of blood donors with symptoms,} patients, and healthy controls

Intensities of pain, fullness, and nausea for the various study groups are shown in fig 3 . Blood donors with gastrointestinal symptoms as well as the patient population had significantly higher symptom scores than healthy controls. Overall, 14 of 48 blood donors with symptoms and 16 of 40 patients with FD or IBS had a symptom response to the standardised nutrient challenge that exceeded the response (mean (2SD)) of healthy asymptomatic controls (table 3).

\section{Symptom type}

Blood donors with dysmotility-type dyspepsia had significantly higher symptom scores for "fullness" than controls, and patients with dysmotility-type dyspepsia also scored significantly higher for "fullness" but also for "nausea" than controls (fig 4). Blood donors with ulcer-type dyspepsia scored higher for "fullness" versus controls. Patients with ulcer-type dyspepsia scored higher for "pain" versus controls (fig 4). Blood donors with IBS symptoms had higher "pain" scores than controls, and patients with IBS symptoms had even higher scores for "pain".

\section{Helicobacter pylori prevalence}

A positive IgG antibody titre for $H$ pylori was found in $50 \%$ (95\% CI 45.3-54.7) of the blood donor population. In blood donors with abdominal symptoms, 47.1\% (95\% CI 34.8-59.6) tested positive for $H$ pylori. In contrast, only 19.4\% (95\% CI 7.5-37.5) of patients tested positive for $H$ pylori.

Neither gastric emptying nor responses to nutrient ingestion were associated with $H$ pylori status (data not shown).

\section{DISCUSSION}

In this combined population of patients with FD and IBS seen at a tertiary referral centre and non-health care seeking subjects with FD or IBS-symptoms, abnormalities of gastric emptying and symptomatic responses to nutrient stimulation were observed and linked to the predominant symptom pattern. Subjects with predominantly dysmotility-type symptoms were characterised by delayed gastric emptying. Subjects with ulcer-type symptoms were more likely to have an augmented pain response to nutrient challenge, suggesting an abnormality of (afferent) sensory function.

It is intriguing that abnormalities of function were found in subjects that had not sought medical attention. Previous studies on gastric emptying and sensory function have been conducted in tertiary referral settings ${ }^{10} 1821$ and the prevalence of delayed gastric emptying in FD has been reported as $20-40 \% .{ }^{12}{ }^{22}$ However, the observed abnormalities of function may not represent a specific feature of patients seen at tertiary referral centres but could be due to referral bias. As we found very similar results in both population based subjects and patients, our data suggest that disturbances of gastric function are not due to referral bias. Whether the observed differences in gastric emptying are of clinical significance remains controversial. Indeed, while we were able to identify statistically significant differences and may

Table 3 Proportion of patients with delayed gastric emptying (GET, $\mathrm{t}_{1 / 2}$ (minutes) $>$ mean of health asymptomatic controls (2SD)) and augmented symptom response after $600 \mathrm{ml}$ of nutrient challenge (VAS $\mathrm{mm}>$ healthy asymptomatic controls (2SD))

\begin{tabular}{lcl}
\hline Predominant symptom & \multicolumn{2}{c}{ Blood donors with symptoms $(\mathbf{n}=\mathbf{4 8})$ Patients $(\mathbf{n}=40)$} \\
\hline Subjects with abnormal gastric emptying/all subjects & \\
All subjects & $25 / 48(52.1 ; 37.2-66.7)$ & $18 / 40(45.0 ; 29.3-61.5)$ \\
Dysmotility-type & $10 / 16(33.3 ; 20.4-48.4)$ & $6 / 9(15.0 ; 5.7-29.8)$ \\
Ulcer-type & $9 / 14(18.8 ; 9.0-32.6)$ & $5 / 13(12.5 ; 4.2-26.8)$ \\
IBS & $6 / 18(12.5 ; 4.7-25.3)$ & $7 / 17(17.5 ; 7.3-32.8)$ \\
Subjects with augmented symptom response/all subjects & \\
All subjects & $14 / 48(29.2 ; 16.9-44.1)$ & $16 / 40(40.0 ; 24.9-56.7)$ \\
Dysmotility-type & $5 / 16(10.4 ; 3.5-23.7)$ & $4 / 9(10.0 ; 2.8-23.7)$ \\
Ulcer-type & $4 / 14(8.3 ; 2.3-20.0)$ & $6 / 13(15.0 ; 5.7-29.8)$ \\
IBS & $5 / 18(10.4 ; 3.5-23.7)$ & $6 / 17(15.0 ; 5.7-29.8)$ \\
\hline
\end{tabular}

Values are number and $(\% ; 95 \%$ confidence interval).

IBS, irritable bowel syndrome. 


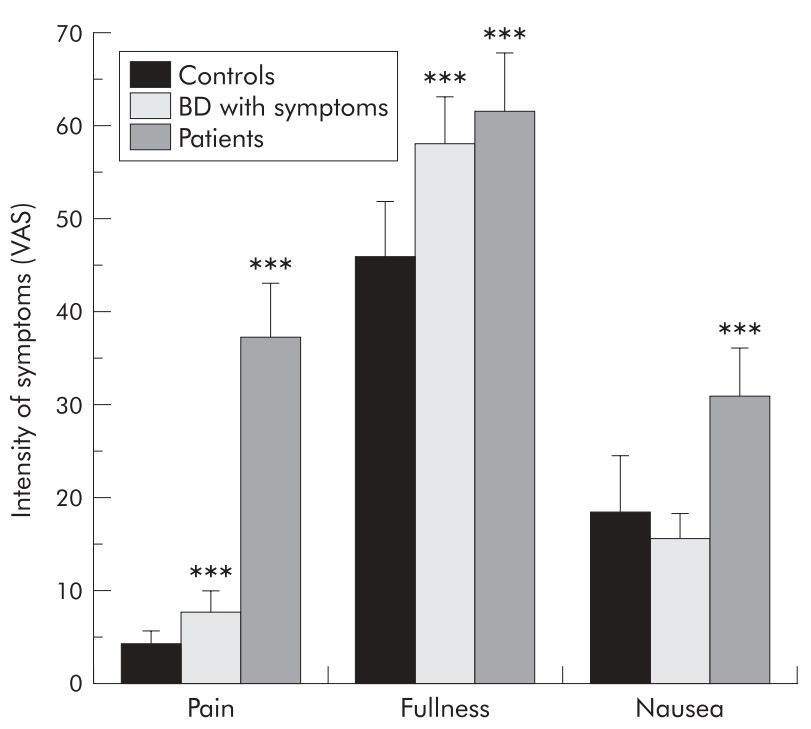

Figure 3 Symptoms after a $600 \mathrm{ml}$ liquid load in blood donors (BD) with symptoms $(n=48)$, healthy controls $(n=20)$, and patients $(n=40)$. Self reported symptoms (visual analogue scale, VAS $(\mathrm{mm})$ ). ${ }^{* * *} \mathrm{p}<0.001$ versus asymptomatic controls.

even have found a subgroup of FD patients with severely delayed GET (>200 minutes), individual values overlapped considerably. It has been reported recently that early satiety was associated with early distal redistribution of the liquid phase and fullness was associated with late proximal retention..$^{23}$ However, Piessevaux and colleagues ${ }^{23}$ reported similar intragastric distribution of a solid test meal in healthy controls and FD patients. The same group reported an association of delayed gastric emptying of liquids with postprandial fullness and with severe early satiety. ${ }^{22}$ Thus it might be argued that even small differences in gastric emptying are related to different pathophysiological mechanisms in a subgroup of FD patients. Thus the data are consistent with the concept that alterations in gastric emptying play a role in the manifestation of symptoms in a subgroup of patients with FD, while other factors may also be important.

It has been reported that non-consulters usually have lower symptom intensities, ${ }^{2}$ and in the present study abnormalities of function were more prevalent and severe in our patient controls. While numerically the proportion of blood donors and patients with abnormal sensory or motor function was not substantially different, patients had more severe disturbances in function compared with blood donors with symptoms. This may point to the fact that the severity of the functional abnormality determines the severity of symptoms and in turn the likelihood of health care utilisation. Recently, Koloski et al ${ }^{24}$ analysed potential predictors of health care seeking behaviour for IBS and FD. They reported that factors other than psychological morbidity, including symptom severity and frequency, were important for health care utilisation. However, there is still an ongoing debate about the relationship between mental health and health care utilisation. Anxiety in particular has been reported to be associated with FD patients ${ }^{25-28}$ but to our knowledge no previous study has assessed the correlation between mental health and visceral nociception.

On the other hand, previous studies were unable to demonstrate an association between normalisation of gastric emptying and improvement in symptoms..$^{29-32}$ Thus while on the one hand it might be argued that abnormalities of gastric emptying can be directly associated with symptoms, it may

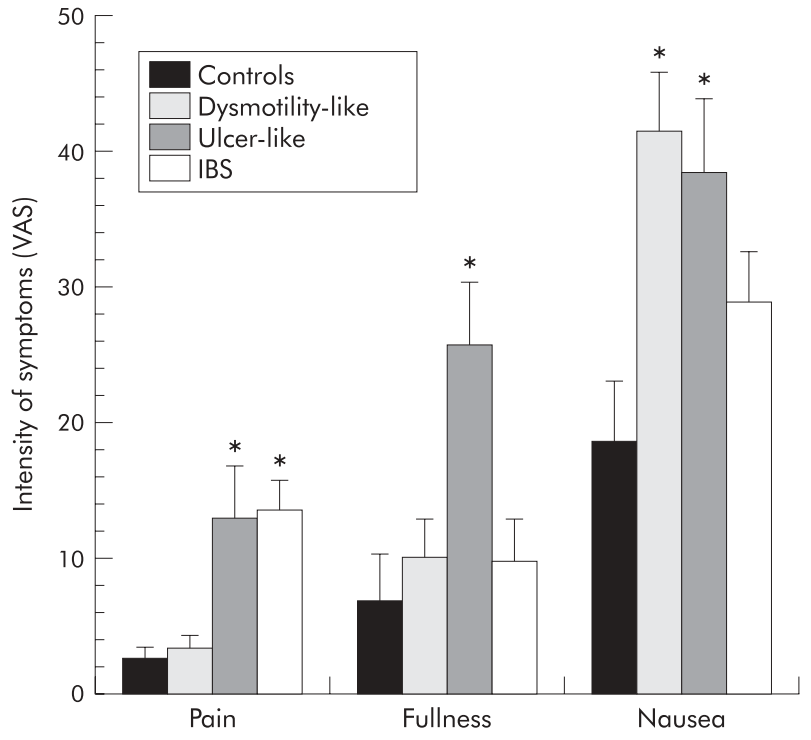

Figure 4 Intensity of gastrointestinal symptoms after a $600 \mathrm{ml}$ liquid nutrient load in groups stratified based on their predominant symptom. Self reported symptoms (visual analogue scale, VAS $(\mathrm{mm})$ ). IBS, irritable bowel syndrome. ${ }^{*} p<0.05$ versus asymptomatic controls.

be that disturbances in gastric emptying are simply a marker for other underlying abnormalities but are not directly relevant for manifestation of symptoms.

We studied a sample of blood donors that should be representative of the general population as well as patients referred to a tertiary referral centre. It is possible that our subjects were not representative of the population of patients in general. However, the distribution of symptom types, and the overlap of symptoms in our study population was very similar to patterns of symptoms reported previously in other patient populations. ${ }^{23-35}$

We wanted to non-invasively assess sensory dysfunction in dyspepsia. Barostat studies are now considered the gold standard for assessment of visceral sensory function. However, the invasive nature of barostat studies clearly limits usability and may cause selection bias. Thus noninvasive methods have been reported to assess accommodation, such as ultrasound studies for the proximal stomach, which are labour intensive and require specialised equipment. ${ }^{36}$ Three dimensional single photon emission computed tomography of the gastric wall was developed for quantification of accommodation but this requires expensive equipment and specialised software and is associated with radiation exposure. ${ }^{37}$ Recently, hyper caloric drinking tests have been reported to be useful in assessing gastric accommodation. $^{31113}$ Some groups have reported high reproducibility and correlation with barostat $^{3} 1319$ while others did not find symptom concordance. ${ }^{11}$ We used the standardised nutrient challenge for assessment of sensory function. In a previous study, ${ }^{19}$ we have validated the approach; we compared this methodology with the "gold standard" barostat technique and could demonstrate that symptom responses were significantly correlated with the results of barostat testing. To our knowledge there are no studies that have compared fractional nutrient challenge with bolus drinks. We decided to use a fractional test because this better reflects real life and should be suitable for assessing mechanosensory function. However, we cannot argue that one method is superior to another with regard to discrimination of patient groups; further investigations regarding this issue are needed. In this context, it must be 
taken into consideration that the liquid nutrient challenge empties from the stomach into the duodenum and thus a concomitant delay in gastric emptying could affect the results. Noteworthy, gastric emptying delivers, on average, between 1 and $1.5 \mathrm{kcal}$ per minute into the duodenum. Hence the relatively small amounts emptied into the duodenum should not have substantially influenced our results. Study subjects ingested the target volume of $600 \mathrm{ml}$ within 15 minutes and caloric density was $1.5 \mathrm{kcal} / \mathrm{ml}$. Therefore, it is highly unlikely that a disturbance in gastric emptying would have affected the results. Indeed, others have validated similar methodology. ${ }^{13}$ On the other hand, disturbed fundic relaxation ${ }^{38}{ }^{39}$ could also have affected our findings, with antral distension occurring as a consequence of a diminished volume response of the proximal stomach. ${ }^{40}$ This in turn may have caused the augmented global symptom response observed in a subset of subjects. Other studies with nutrient test meals have used different caloric loads or time intervals over which the meal was ingested. ${ }^{13}$ As we have previously validated our methodology ${ }^{19}$ and our results are in line with other findings in consulters and non-consulters investigated with either a liquid meal ${ }^{13}$ or by barostat, ${ }^{6}$ we conclude that differences in the methodology are unlikely to have substantially affected the results.

Assessment of symptoms and categorisation of patients is a key issue. Importantly, in this study strict criteria were applied for assessment of the most bothersome symptom pattern for the first time. Dysmotility-type dyspepsia was linked to delayed gastric emptying. We also found a higher symptom score for fullness and nausea in patients with dysmotility-type FD after a nutrient load. We cannot determine whether delayed emptying of the test meal caused an augmented symptom response or whether visceral sensitivity or fundic disaccomodation contributed to the altered symptom response. A combination of various mechanisms is most likely the explanation of the remarkable overlap of symptoms. ${ }^{41}{ }^{42}$ Interestingly, patients with predominantly ulcer-type dyspepsia also scored higher for fullness. This also argues in favour of a common mechanism in the various disease subgroups. We did not find any significant differences between blood donors and patients with IBS symptoms, most likely due to the small sample size.

GORD frequently overlaps with FD and, even in the absence of mucosal lesions, GORD can be the cause of upper abdominal symptoms. Thus this issue needs careful consideration. In the present study, however, patients with a history of structural lesions such as peptic ulcers or other peptic lesions, were not eligible for participation in the study. Furthermore, all patients with GORD symptoms only or patients with predominantly GORD symptoms were excluded. Thus it is reasonable to assume that our findings are not due to contamination of our study population with GORD patients.

In blood donors, the prevalence of $H$ pylori was $48 \%$. Thus it cannot be excluded that $H$ pylori associated structural lesions were present as the cause of symptoms in at least some controls. However, it is unlikely that this would have influenced our results as previous studies in $H$ pylori positive blood donors rarely found peptic ulcers ${ }^{43}$ In addition, such effects would most likely only have blunted any differences. Furthermore, in line with previous findings, $H$ pylori was neither associated with a specific symptom pattern ${ }^{16}$ nor did we observe any differences between $H$ pylori positive and negative subjects regarding gastric emptying and the symptomatic response to the test meal. Our findings related to gastric emptying and $H$ pylori are in line with most investigations in patients ${ }^{44}{ }^{45}$ but not all. ${ }^{46}$ Thus the observed association of symptom patterns with abnormalities of function appears to be reasonable robust.
While $19 \%$ of patients tested positive for $H$ pylori, slightly more than half of the blood donors tested positive for $\mathrm{H}$ pylori IgG antibodies. The significant difference between our blood donor population and patients might be explained by the efforts of referring physicians to treat symptoms by $H$ pylori eradication that failed to control symptoms. Thus the positive control (patients) may represent a group of patients who are refractory to conventional therapeutic measures. This must be kept in mind when differences in primary outcome parameters are being considered.

In summary, abnormalities of gastric emptying and augmented symptom responses to a standardised nutrient challenge (reflecting abnormalities of sensory function, disturbances of fundic relaxation, or both) were highly prevalent in blood donors with relapsing unexplained gastrointestinal symptoms and patients with functional gastrointestinal disorders. Disturbances in function however were more severely impaired in patients compared with nonhealth care seeking blood donors with symptoms.

\section{Authors' affiliations}

S Haag, G Holtmann, Department of Internal Medicine, Division of Gastroenterology and Hepatology, University Hospital Essen,

Hufelandstr 55, D-45122 Essen, Germany

N J Talley, Mayo Clinic, College of Medicine, Rochester, MN, USA

\section{REFERENCES}

1 Talley NJ, Stanghellini V, Heading RC, et al. Functional gastroduodenal disorders. Gut 1999;45(suppl 2):॥37-42.

2 Holtmann G, Goebell H, Talley NJ. Dyspepsia in consulters and nonconsulters: prevalence, health-care seeking behavior and risk factors. Eur J Gastroenterol Hepatol 1994;6:917-24.

3 Tack J, Piessevaux $\mathrm{H}$, Coulie B, et al. Role of impaired gastric accommodation to a meal in functional dyspepsia. Gastroenterology 1998;115:1346-52.

4 Thumshirn M, Camilleri M, Saslow SB, et al. Gastric accommodation in nonulcer dyspepsia and the roles of Helicobacter pylori infection and vagal function. Gut 1999;44:55-64.

5 Holtmann G, Goebell H, Jockenhoevel F, et al. Altered vagal and intestinal mechanosensory function in chronic unexplained dyspepsia. Gut 1998;42:501-6.

6 Holtmann G, Gschossmann J, Neufang-Huber J, et al. Differences in gastric mechanosensory function after repeated ramp distensions in non-consulters with dyspepsia and healthy controls. Gut 2000;47:332-6.

7 Malagelada JR. Gastrointestinal motor disturbances in functional dyspepsia. Scand J Gastroenterol Suppl 1991;182:29-32.

8 Mayer EA, Raybould HE. Role of visceral afferent mechanisms in functional bowel disorders. Gastroenterology 1990;99:1688-704.

9 Mayer EA, Gebhart GF. Basic and clinical aspects of visceral hyperalgesia. Gastroenterology 1994;107:271-93.

10 Stanghellini V, Tosetti C, Barbara G, et al. Risk indicators of delayed gastric emptying of solids in patients with functional dyspepsia. Gastroenterology 1996; 110:1036-42.

11 Boeckxstaens GE, Hirsch DP, van den Elzen BD, et al. Impaired drinking capacity in patients with functional dyspepsia: relationship with proximal stomach function. Gastroenterology 2001;121:1054-63.

12 Talley NJ, Verlinden M, Jones M. Can symptoms discriminate among those with delayed or normal gastric emptying in dysmotility-like dyspepsia? Am J Gastroenterol 2001;96:1422-8.

13 Tack J, Caenepeel P, Piessevaux H, et al. Assessment of meal induced gastric accommodation by a satiety drinking test in health and in severe functional dyspepsia. Gut 2003;52:1271-7.

14 Blaser MJ, Duncan DJ. Human serum antibody response to Campylobacter jejuni infection as measured in an enzyme-linked immunosorbent assay. Infect Immun 1984;44:292-8.

15 Talley NJ, Phillips SF, Melton J iii, et al. A patient questionnaire to identify bowel disease. Ann Intern Med 1989;111:671-4.

16 Holtmann G, Goebell H, Holtmann M, et al. Dyspepsia in healthy blood donors. Pattern of symptoms and association with Helicobacter pylori. Dig Dis Sci 1994;39:1090-8.

17 Drossman DA. The functional gastrointestinal disorders and the Rome II process. Gut 1999;45(suppl 2):II1-5.

18 Ghoos YF, Maes BD, Geypens BJ, et al. Measurement of gastric emptying rate of solids by means of a carbon-labeled octanoic acid breath test. Gastroenterology 1993;104:1640-7.

19 Holtmann G, Talley NJ, Neufang-Hüber J, et al. Comparison of gastric mechanosensory thresholds and maximal tolerance of a liquid meal. Gastroenterology 1996;110:A680.

20 SAS Institute Inc. SAS/STAT Software. Changes and enhancements through release 6.12. Cary, NC: SAS Institute, 1997 
21 Camilleri M, Brown ML, Malagelada JR. Relationship between impaired gastric emptying and abnormal gastrointestinal motility. Gastroenterology 1986;91:94-9.

22 Sarnelli G, Caenepeel P, Geypens B, et al. Symptoms associated with impaired gastric emptying of solids and liquids in functional dyspepsia. Am J Gastroenterol 2003;98:783-8.

23 Piessevaux H, Tack J, Walrand S, et al. Intragastric distribution of a standardized meal in health and functional dyspepsia: correlation with specific symptoms. Neurogastroenterol Motil 2003;15:447-55.

24 Koloski NA, Talley NJ, Huskic SS, et al. Predictors of conventional and alternative health care seeking for irritable bowel syndrome and functional dyspepsia. Aliment Pharmacol Ther 2003;17:841-51.

25 Kettell J, Jones R, Lydeard S. Reasons for consultation in irritable bowel syndrome: symptoms and patient characteristics. Br J Gen Pract 1992;42:459-61.

26 Cheng C. Seeking medical consultation: perceptual and behavioral characteristics distinguishing consulters and nonconsulters with functional dyspepsia. Psychosom Med 2000;62:844-52.

27 Westbrook JI, Mclntosh J, Talley NJ. Factors associated with consulting medical or non-medical practitioners for dyspepsia: an Australian populationbased study. Aliment Pharmacol Ther 2000;14:1581-8.

28 Lydeard S, Jones R. Factors affecting the decision to consult with dyspepsia: comparison of consulters and non-consulters. J R Coll Gen Pract 1989:39:495-8.

29 Corinaldesi R, Stanghellini V, Raiti C, et al. Effect of chronic administration of cisapride on gastric emptying of a solid meal and on dyspeptic symptoms in patients with idiopathic gastroparesis. Gut 1987;28:300-5.

30 Sturm A, Holtmann G, Goebell H, et al. Prokinetics in patients with gastroparesis: a systematic analysis. Digestion 1999;60:422-7.

31 Talley NJ, Verlinden M, Snape W, et al. Failure of a motilin receptor agonist (ABT-229) to relieve the symptoms of functional dyspepsia in patients with and without delayed gastric emptying: a randomized double-blind placebo-controlled trial. Aliment Pharmacol Ther 2000;14:1653-61.

32 Veldhuyzen van Zanten SJ, Jones MJ, Verlinden M, et al. Efficacy of cisapride and domperidone in functional (nonulcer) dyspepsia: a meta-analysis. Am J Gastroenterol 2001;96:689-96.
33 Agreus L, Talley NJ, Svardsudd K, et al. Identifying dyspepsia and irritable bowel syndrome: the value of pain or discomfort, and bowel habit descriptors. Scand J Gastroenterol 2000;35:142-51.

34 Talley NJ, Zinsmeister AR, Schleck CD, et al. Dyspepsia and dyspepsia subgroups: a population-based study. Gastroenterology 1992;102:1259-68.

35 Talley NJ, Holtmann G, Agreus L, et al. Gastrointestinal symptoms and subjects cluster into distinct upper and lower groupings in the community: a four nations study. Am J Gastroenterol 2000;95:1439-47.

36 Whitehead WE, Delvaux M. Standardization of barostat procedures for testing smooth muscle tone and sensory thresholds in the gastrointestinal tract. The Working Team of Glaxo-Wellcome Research, UK. Dig Dis Sci 1997; 42:223-41.

37 Kuiken SD, Samsom M, Camilleri M, et al. Development of a test to measure gastric accommodation in humans. Am J Physiol 1999;277:G1217-21.

38 Ahluwalia NK, Thompson DG, Barlow J, et al. Relaxation responses of the human proximal stomach to distension during fasting and after food. Am J Physiol 1994;267:G166-72.

39 Hartley MN, Mackie CR. Gastric adaptive relaxation and symptoms after vagotomy. Br J Surg 1991;78:24-7.

40 Kerlin P. Postprandial antral hypomotility in patients with idiopathic nausea and vomiting. Gut 1989;30:54-9.

41 Agreus L, Svardsudd K, Nyren O, et al. Irritable bowel syndrome and dyspepsia in the general population: overlap and lack of stability over time. Gastroenterology 1995:109:671-80.

42 Grainger SL, Klass HJ, Rake MO, et al. Prevalence of dyspepsia: the epidemiology of overlapping symptoms. Postgrad Med J 1994;70:154-61. 43 Vaira D, Miglioli M, Mule P, et al. Prevalence of peptic ulcer in Helicobacter pylori positive blood donors. Gut 1994;35:309-12.

44 Chang CS, Chen $\mathrm{GH}$, Kao $\mathrm{CH}$, et al. Delayed gastric emptying does not predispose to Helicobacter pylori infection in non-ulcer dyspepsia patients. Nucl Med Commun 1995;16:1063-7.

45 Scott AM, Kellow JE, Shuter B, et al. Intragastric distribution and gastric emptying of solids and liquids in functional dyspepsia. Lack of influence of symptom subgroups and $\mathrm{H}$. pylori-associated gastritis. Dig Dis Sci 1993;38:2247-54

46 Wegener M, Borsch G, Schaffstein J, et al. Are dyspeptic symptoms in patients with Campylobacter pylori-associated type B gastritis linked to delayed gastric emptying? Am J Gastroenterol 1988;83:737-40.

\section{EDITOR'S QUIZ: GI SNAPSHOT Answer}

From question on page 1444

Computerised tomograpy scan shows a highly vascularised mass on the body of the pancreas. She also had a basal plasma glucagon concentration of $1100 \mathrm{pg} / \mathrm{ml}$ and serum zinc level of $97 \mu \mathrm{g} / \mathrm{dl}$. Necrolytic migratory erythema (NME) is an uncommon condition sometimes associated with high plasma levels of circulating glucagon and other metabolic changes, and characterised by an islet alpha cell pancreatic tumour, NME, diabetes mellitus, weight loss, anaemia, stomatitis, thromboembolism, and gastrointestinal and neuropsychiatric disturbances. Glucagon itself is responsible for most of the observed signs and symptoms, and its induction of hypoaminoacidaemia is thought to lead to NME. Liver disease and fatty acid and zinc deficiency states may also contribute. Most patients are diagnosed too late but successful palliation of symptoms can usually be achieved with surgical and medical intervention. Glucagonomas express somatostatin receptors in more than $80 \%$ of cases. In-111 DTPA N-terminal D-phenylalanine (D-PHEl) octreotide for glucagonoma imaging may be most beneficial as an adjuvant to conventional imaging for tumour staging and therapeutic decision making. In the presence of metastatic disease, crioablation, chemoembolisation, and operative procedures in selected cases are under evaluation. 